\title{
Effect of Colorant Solutions on the Color Stability of Provisional Prosthetic Materials
}

\author{
Ítalo Alisson da Fonsêca Costa ${ }^{1}$, Emilena Maria \\ Castor Xisto Lima ${ }^{2}$
}

\begin{abstract}
'Specialist in Dental Prosthesis Bahiana School of Medicine and Public Health, Salvador, Bahia, Brazil

${ }^{2}$ Adjunct Professor - Bahiana School of Medicine and Public Health and Faculty of Dentistry of Federal University of Bahia, Salvador, Bahia, Brazil
\end{abstract}

Corresponding author:

Emilena Maria Castor Xisto Lima Address: Rua Waldemar Falcão,

n. 1906, Torre Paysage, apt. 1402 Horto Florestal

Salvador - Bahia CEP - 40295-010

Brazil

Tel: +55 (71) 99194-6656

E-mail: emilenalima@gmail.com

Received: December 28, 2017

Accepted: March 28, 2018
Aim: To evaluate the color stability of acrylic and bis-acrylic resins after immersion in 3 staining solutions. Methods: Forty-eight samples $(10 \times 2 \mathrm{~mm})$ of each provisional restorative material (Duralay, Dencrilay, Structur 2 and Protemp 4) were fabricated and distributed into four groups ( $n=12)$ : G1 - distilled water (control group); G2 - a cola flavored soft drink; G3 - wine and G4 - coffee. The specimens were immersed for seven days at $37^{\circ} \mathrm{C}$ in the solutions, which were changed every 24 hours. The color of all specimens was measured with a spectrophotometer (VITA Easyshade Advance) before (T0) and after immersion (T1), and the color changes $(\triangle E)$ were calculated. Nonparametric Kruskal-Wallis tests were used, followed by Dunn's test with a significance level of $5 \%$. Results: For the acrylic resins (Duralay and Dencrilay), the largest color change values were obtained in group G4 - coffee, whereas in the bis-acrylic resins (Protemp 4 and Structur 2), the largest color difference was observed in groups G3 - wine and G4 - coffee. The acrylic resins showed statistically significantly less color change than the bis-acrylic resins. Conclusions: The coffee and the wine promoted larger color changes in the provisional prosthetic materials tested in this study. The acrylic resins showed more color stability than the bis-acrylic resins.

Keywords: Color. Solutions. Dental Restoration, Temporary. 


\section{Introduction}

The provisional phase of oral rehabilitation is the longest and decisive stage of prosthetic treatment. Therefore, temporary crowns and fixed prostheses should be adequate to provide comfort, hygiene, health and aesthetic satisfaction to the patient during this period. For this, both the material and its fabrication method must be carefully chosen to maintain surface smoothness, mechanical resistance and color stability properties that are favorable to the success of the treatment.

The dental material most used in the manufacturing of temporary fixed prostheses are acrylic resins due to their resistance, color stability, polishing properties and, especially, low cost ${ }^{1}$. Additionally, bis-acrylic resins have been developed to minimize the adverse effects of acrylic resins; thus, they have improved mechanical stability, are biocompatible, are easy to handle (available in base paste / catalyst), have a less exothermic reaction and release fewer monomer residues ${ }^{2}$. Therefore, these resins cause less pulpal and periodontal irritation, which favors a better contour and the marginal adaptation of the provisional prostheses ${ }^{3,4}$

Regardless of the chosen material, the aesthetic quality of provisional prostheses is fundamentally important for patient satisfaction and should approach the full form and color of the natural teeth ${ }^{5}$. Despite the quality of dental materials that are available in the dental market, none of them can exactly maintain their original color as they are subjected to various chemical substances, foods and dying solutions during treatment. The color change may still be affected by the material type that is used incomplete polymerization and oral hygiene of the patient. Such a change may result in poor cosmetic appearance and subsequently cause patient dissatisfaction and even additional costs for its replacement ${ }^{6,7}$.

According to Reis et al. ${ }^{8}$ (2003) the intrinsic color of aesthetic materials can be altered when these materials are aged under various physical-chemical conditions, such as thermal and humidity changes. Extrinsic factors are related to the adsorption or absorption of dyes from food or substance intake.

In practice, the use of provisional restorations could extend from several weeks to a half a year ${ }^{9}$. The ability of the tooth-colored restorative materials used for provisional restorations to maintain their color stability is important when temporary prostheses are worn for a long period ${ }^{10}$. As a rule, the longer the material is exposed to various surrounding factors, the greater the chance for color alteration and material wear ${ }^{3}$.

Although studies ${ }^{1,5,7}$ have evaluated the color stability of resin-based materials used for provisional prosthodontic restorations, these materials were subjected to coffee, tea or wine as the staining solutions. However, the effect of soft drink, wine and coffee on color difference of provisional restorative materials has not been completely clarified. These staining solutions that served as means for storage of the specimens were chosen based on the frequency of ingestion of the population and the potential for staining.

Thus, the aim of this study was to evaluate the color stability of acrylic (Duralay and Dencrilay) and bis-acrylic resins (Protemp 4 and Structur 2) after immersion in different solutions: water, cola-flavored soft drink, wine and coffee. 


\section{Material and Methods}

Provisional prosthetic materials used are listed in Table 1.

Table 1. Provisional prosthetic materials used in the study.

\begin{tabular}{lcccc}
\hline Material & Composition & Color & Manufacturer \\
\hline Duralay & $\begin{array}{c}\text { Copolymer of plasticizable methacrylate, } \\
\text { methylmethacrylate monomer, paraffin, mineral oil }\end{array}$ & 62 & Reliance, Cotia-SP, Brazil \\
\hline Dencrilay & $\begin{array}{c}\text { Methyl methacrylate, butyl acrylate, benzoyl } \\
\text { peroxide, ethylene glycol, pigments }\end{array}$ & 62 & Dencril, São Paulo-SP, Brazil \\
\hline Protemp 4 & $\begin{array}{c}\text { Dimethacrylate polymer. Bis-GMA, zirconium } \\
\text { particles, silica and silane, pigments }\end{array}$ & A2 & 3 M ESPE AG, Seefeld, Germany \\
\hline Structur 2 & $\begin{array}{c}\text { Bis-GMA, BHT, amines, benzoyl peroxide, } \\
\text { dimethacrylates, glass particles }\end{array}$ & A2 & Voco, Cuxhaven, Germany \\
\hline
\end{tabular}

A total of 192 samples were fabricated: 48 samples of each material using circular stainless steel molds that were $10 \mathrm{~mm}$ in diameter and $2 \mathrm{~mm}$ in high. Each material was mixed and polymerized according to the manufacturer's instructions. The acrylic resin was inserted in a single increment in the mold. The insertion of bis-acrylic resins in the mold was achieved using the respective dispenser and selfmixer tips of each manufacturer.

A polyester strip and a glass plate were placed over the stainless steel mold to promote removal of the excess material and to ensure a flat and parallel surface to facilitate the reading of the samples.

After the curing period, the samples were removed, and according to the manufacturer's instructions, the bis-acrylic resin samples were subjected to rubbing with a gauze soaked in alcohol (for removal of the inhibiting layer) for $20 \mathrm{~s}$.

Specimens were stored in distilled water for 24 hours at $37^{\circ} \mathrm{C}$. The rehydration was simulated during the first day of service for provisional restorations in an oral environment ${ }^{3,6,7}$.

Baseline CIE (Commission Internationale de l'Eclairage) $L^{*} a^{*} b^{\star}$ color coordinates were established using a spectrophotometer VITA Easyshade® (VITA Zahnfabrik, Bäd Sackingen, Germany) for every specimen before its exposure to a staining agent. The $L{ }^{*} a{ }^{*} b^{*}$ coordinates are relative to a standard illuminant $A$ against a white background. $L^{*}$ refers to the lightness coordinate with a value ranging from zero (black) to 100 (white). The values $a^{*}$ and $b^{*}$ are chromaticity coordinates in the red-green and yellow-blue axes, respectively. Positive $a^{\star}$ values indicate a shift to red, and negative values indicate a shift to green. Similarly, positive $b^{*}$ values indicate the yellow color range, and negative values indicate the blue color range ${ }^{11}$.

The measurements were repeated 3 times for each specimen, and the mean values of the $L^{*}, a^{*}$, and $b^{*}$ data were calculated. To obtain the baseline color data, a custom-made silicone (Elite HD + Putty Soft Normal - Zhermach) holder ${ }^{7}$ was used to hold the specimen, and the tip of the spectrophotometer was surrounded by a PVC pipe containing 
addition silicone during the color measurement to minimize the influence of external light through the edge of the specimen. Furthermore, the tip of the spectrophotometer rested on the same point of the specimens during every color measurement.

After the baseline color measurements were made, the specimens were distributed into 4 groups ( $n=12)$ : G1 (control) - distilled water (Amazonas Comércio e Indústria de Produtos Químicos Ltda., Feira de Santana, Bahia, Brazil); G2 - a cola-flavored soft drink (Coca Cola, Curitiba, PR, Brazil); G3 - wine (Dry Red Table, Campo Largo, Campo Largo, Campo Largo, Curitiba, PR, Brazil); and G4 - coffee (Nescafé Tradicional Instantâneo, Nestlé Brasil Ltda., Araras, SP, Brazil) (Table 2). The coffee (3.6 g) was dissolved in 300 $\mathrm{mL}$ of boiling distilled water according to the manufacturer's suggested concentration ${ }^{12}$. After 10 min of stirring, the solution was filtered through a filter paper.

The specimens were suspended by orthodontic wires in 24-well plates containing $2.5 \mathrm{ml}$ of solution in each well so that all their surfaces remained in contact with the staining solution. Grouped specimens were immersed into specified liquids for 7 days and stored in bath at $37^{\circ} \mathrm{C}^{6,7}$. Every 24 hours the solutions were changed. After 7 days, the specimens were rinsed with water and blotted dry with tissue paper ${ }^{3,10}$ before the color measurement.

Each specimen's color was evaluated in the same manner prior to exposure. The calculation of the color variation $\Delta \mathrm{E}^{*}$ between the 2 color measurements (after 7 days storage and baseline) was performed through the standard formula of the CIE Lab model: $\Delta E L^{*} a^{*} b^{*}=\left[\left(\Delta L^{*}\right)^{2}+(\Delta a *)^{2}+\left(\Delta b^{*}\right)^{2}\right]^{7}$.

The data were checked to ensure normality and homogeneity in the variance by the Shapiro-Wilk and Levene tests. Afterward, the non-parametric Kruskal-Wallis, followed by the Dunn test, were used at a $5 \%$ level of significance. The statistical calculations were carried out with SPSS - Statistical Package for Social Sciences (SPSS Inc., Chicago, IL).

\section{Results}

The color changes (mean $\Delta E$ values) of provisional materials after exposure to different staining solutions are presented in Table 2.

Table 2. Mean and standard deviation of color changes $(\Delta \mathrm{E})$ of acrylic and bis-acrylic resins submitted to different staining solutions.

\begin{tabular}{|c|c|c|c|c|c|c|}
\hline & & $\begin{array}{c}\text { G1 - control } \\
\text { (water) }\end{array}$ & $\begin{array}{c}\text { G } 2 \text { - cola-flavored } \\
\text { soft drink }\end{array}$ & G 3 - wine & G4 - coffee & p-value \\
\hline Duralay & $\begin{array}{c}\text { Mean } \Delta E \\
\text { DP }\end{array}$ & $\begin{array}{c}0.52^{\mathrm{Aa}} \\
0.74\end{array}$ & $\begin{array}{c}1.08^{\mathrm{Aa}} \\
1.12\end{array}$ & $\begin{array}{c}0.94^{\mathrm{Aa}} \\
0.84\end{array}$ & $\begin{array}{c}3.92^{\mathrm{Ba}} \\
2.43\end{array}$ & $<0.001$ \\
\hline Dencrilay & $\begin{array}{c}\text { Mean } \Delta E \\
\text { DP }\end{array}$ & $\begin{array}{c}0.82^{\mathrm{Aa}} \\
0.77\end{array}$ & $\begin{array}{c}1.15^{\mathrm{AB} a} \\
0.93\end{array}$ & $\begin{array}{c}2.61^{\mathrm{AB} a} \\
2.10\end{array}$ & $\begin{array}{c}5.17^{\mathrm{B} \mathrm{a}} \\
4.38\end{array}$ & 0.002 \\
\hline Protemp 4 & $\begin{array}{c}\text { Mean } \Delta E \\
\text { DP }\end{array}$ & $\begin{array}{l}1.95^{\mathrm{Ab}} \\
1.36\end{array}$ & $\begin{array}{c}4.71^{\mathrm{Ab}} \\
3.36\end{array}$ & $\begin{array}{c}11.73^{\mathrm{B} \mathrm{b}} \\
3.47\end{array}$ & $\begin{array}{c}10.60^{\mathrm{Bb}} \\
1.66\end{array}$ & $<0.001$ \\
\hline Structur 2 & $\begin{array}{c}\text { Mean } \Delta E \\
\text { DP }\end{array}$ & $\begin{array}{c}2.69^{A b} \\
1.76\end{array}$ & $\begin{array}{c}3.58^{\mathrm{Ab}} \\
0.75\end{array}$ & $\begin{array}{c}10.70^{\mathrm{Bb}} \\
3.59\end{array}$ & $\begin{array}{c}11.07^{\mathrm{Bb}} \\
1.82\end{array}$ & $<0.001$ \\
\hline $\mathrm{p}$-value & & 0.002 & $<0,001$ & $<0.001$ & $<0.001$ & \\
\hline
\end{tabular}

Different letters (lowercase in columns and uppercase in rows) indicate statistically significant differences $(p<0.05$. Kruskal-Wallis, Dunn). 
When comparing the different solutions, for the acrylic resin Duralay, the largest color-change values were observed in group 4 - coffee, which was found to be significantly different compared with values obtained in the other groups.

For the acrylic resin Dencrilay, there was no statistically significant difference between groups 2, 3 and 4. For the bis-acrylic resins (Protemp 4 and Structur 2), the largest color differences were observed in groups 3 and 4 , which were not significantly different from each other.

When comparing the four different provisional prosthetic materials, the acrylic resins demonstrated statistically significant less color change compared with the bis-acrylic resins. The acrylic resins (Duralay and Dencrilay) were not significantly different from each other as well as bis-acrylic resins (Protemp 4 and Structur 2).

\section{Discussion}

The staining of dental materials is the result of both extrinsic (surface roughness, poor oral hygiene, nutrition, and material wear) and intrinsic (filler and monomer composition, residual unpolymerized monomers resulting from incomplete polymerization) factors $8,13,14$

Extrinsic factors for color alteration include staining by colorant adsorption or absorption because of contamination from exogenous sources ${ }^{15}$. Additionally, extrinsic factors for color alteration are known to cause staining of oral tissues and restorations, especially in combination with dietary factors. Among these, coffee, tea, nicotine, and beverages have been reported ${ }^{15,16}$. The solutions used in the study (a soft drink, coffee, wine) were chosen because of the high frequency of ingestion by the population and high potential for staining.

According to Koishi et al. ${ }^{17}$ (2001), the thickness and smoothness of the specimen surface also affect color. In the present study, the thickness of provisional restorative material specimens was $2 \mathrm{~mm}^{2}$. However, because the calculation of the color variation $\left(\Delta E^{\star}\right.$ ) between 2 color positions (7-day storage and baseline) in the 3-D $L^{\star} a^{\star} b^{\star}$ color space was investigated, the thickness of the specimens was not important.

In practice, the use of a provisional prosthesis may extend from a few days to six months or more, indicating that a low quality of provisional restorations can bring complications, dissatisfaction and even additional costs for its replacement6,7,9,10.

As a rule, the longer the material is exposed to various factors (diet, oral hygiene, water sorption, and chemical reactivity), the greater the chances for color alteration and increased roughness ${ }^{7}$. The period of immersion in the solutions was 7 days, and according to Guler et al. ${ }^{3}$ (2005), the coffee manufacturer purports that the average time for consumption of 1 cup of a drink is 15 minutes, and among coffee drinkers, the average consumption of coffee is 3.2 cups per day. Therefore, 24 hours of immersion of samples in coffee simulate consumption of the drink over 1 month. The storage for 7 days was selected as a standard time and correspond to seven months of provisional phase treatment.

In this study, a color change was verified in all the resins regardless of the solution used, but G3 - wine and G4 - coffee promoted greater variable color changes in the 
samples. These solutions elevated the $\Delta E$ of the samples to values that are higher than clinically acceptable values. According to Johnston and Kao' (1989), the size of the color difference, which is larger than $\triangle \mathrm{E} 3.7 \mathrm{E}$ units, is the highest value that has been determined as clinically acceptable.

The influence of coffee and wine on the color change was observed in other studies. Rutkunas et al. ${ }^{7}$ (2010) verified that bis-acryl composite resins exhibited more significant color changes in coffee with sugar and in red wine compared with methyl/ethyl methacrylates. These results agree with the bis-acryl resin results in this study.

The color stability in acrylic and bis-acrylic resins was also evaluated by Haselton et al. ${ }^{1}$ (2005). This group analysed in vitro 12 prosthetic materials that were immersed in pure artificial saliva and coffee at $37^{\circ} \mathrm{C}$ after 1,2 and 4 weeks. The results verified that the Luxatemp, Protemp and Temphase bis-acrylic resins obtained more impactful color change results in coffee than in pure saliva. In the present study, group 4 - coffee promoted a significant color change compared with wine in the acrylic resin Duralay, but there was no difference between coffee and wine in the other materials.

In the present study, the bis-acrylic resins demonstrated statistically significantly more color change compared with the acrylic resins. These results agree with the study of Rutkunas et al. ${ }^{7}$ (2010). They investigated the effects of different polishing techniques on the color stability of provisional prosthetic materials upon exposure to different staining agents (distilled water (control), food colorant, coffee and red wine) and verified that bis-acryl composite resins compared with methyl/ethyl methacrylates exhibited more significant color changes in coffee with sugar and in red wine. Additionally, Givens et al. ${ }^{5}$ (2008) evaluated the color stability of two autocured bis-acryl materials. One dual-cure bis-acryl material and one PEMA control material were immersed cyclically in tea for 1 week, and the results verified that of the four materials, only Protemp Garant, an autocured bis-acryl composite, exhibited a clinically noticeable change in shade.

Several studies have reported that water absorption is influenced by factors such as filler content ${ }^{19,20}$, the presence of residual unpolymerized monomers, the inclusion of air bubbles ${ }^{21,22}$ and the cross-linking degree of resin molecules ${ }^{23,24}$. In particular, incomplete polymerization might cause a deterioration in physical properties of the resin material and an increase in microleakage, thereby inducing color changes.

In the present study, the results showed a greater vulnerability of the bis-acryl resins in relation to color changes. Several authors ${ }^{1,5,10}$ associate this characteristic to the composition of the bis-acryl resins. According to Haselton et al. ${ }^{1}$ (2005), most bis-acryl polymers are more polar than PMMA polymers and therefore have a greater affinity towards water and other polar liquids.

Thus, there is a greater absorption of liquids in bisacrylic resins that favors the incorporation of pigments that are contained in these liquids. This phenomenon is probably the reason for the larger color changes in bis-acryl resins that were found in this study.

The results suggest that during provisional phase of treatment, the patient should avoid staining drinks. When provisional fixed prosthodontic materials are used for long periods, the acrylic resin tested may be preferred over the bisacrylic resins for 
areas that aesthetic is important and the long time of provisional phase is necessary. In other hand, bis-acrylic resin is the option for short time provisional phase or in case of long time in area that aesthetic is no relevant.

In view of the diversity of information available in the scientific literature on the aesthetic characteristics of provisional prosthetic materials, further studies are necessary, since the color change of these materials is a reality that must be carefully observed and monitored by the professional to obtain dental rehabilitation success.

Within the limitations of this study, it could be concluded that: both coffee and wine promoted larger color changes in the provisional prosthetic materials tested in this study. The acrylic resins showed more color stability than the bis-acrylic resins.

\section{References}

1. Haselton DR, Diaz- Arnald AM, Dawson DV. Color stability of provisional crown and fixed partial denture resins. J Prosthet Dent. 2005 Jan;93(1):70-5.

2. Strassler HE, Lowe RA. Chairside resin-based provisional restorative materials for fixed prosthodontics. Compend Contin Educ Dent. 2011 Nov-Dec;32(9):10, 12, 14 passim; quiz 20, 38.

3. Guler AU, Yilmaz F, Kulunk T, Guler E, Kurt S. Effects of different drinks on stainability of resin composite provisional restorative materials. J Prosthet Dent. 2005 Aug;94(2):118-24

4. Perry RD, Magnuson B. Provisional Materials: Key components of interim fixed restorations. Compend Contin Educ Dent. 2012 Jan;33(1):59-60, 62

5. Givens EJ Jr, Neiva G, Yaman P, Dennison JB. Marginal adaption and color stability of four provisional materials. J Prosthodont. 2008 Feb;17(2):97-101. doi: 10.1111/j.1532-849X.2007.00256.x.

6. Rutkünas V, Sabaliauskas V. Effects of different repolishing techniques of colour change of provisional prosthetic materials. Stomatologija. 2009;11(4):105-12

7. Rutkunas V, Sabaliauskas V, Mizutani H. Effects of different food colorants and polishing techniques on color stability of provisional prosthetic materials. Dent Mater. 2010 Mar;29(2):167-76.

8. Reis AF, Giannini M, Lovadino JR, Ambrosano GM. Effects of various finishing systems on the surface roughness and staining susceptibility of packable composite resins. Dent Mater. 2003 Jan;19(1):12-8

9. Scotti R, Mascellani SC, Forniti F. The in vitro color stability of acrylic resins for provisional restorations. Int J Prosthodont. 1997 Mar-Apr;10(2):164-8.

10. Sham ASK, Chu FCS, Chai J, Chow TW. Color stability of provisional prosthodontic materials. J Prosthet Dent. 2004 May;91(5):447-52.

11. Commission Internationale De L'Eclairage. Technical Report. Colorimetry. 3rd ed. Vienna: CIE Central Bureau; 2004. CIE 15

12. Guler AU, Kurt S, Kulunk T. Effects of various finishing procedures on the staining of provisional restorative materials. J Prosthet Dent. 2005 May;93(5):453-8.

13. Yap AU, Lee HK, Sabapathy R. Release of methacrylic acid from dental composites. Dent Mater. 2000 May; 16(3):172-9.

14. Oréfice RL, Discacciati JAC, Neves AD, Mansur HS, Jansen WC. In situ evaluation of the polymerization kinetics and corresponding evolution of the mechanical properties of dental composites. Polym Test. 2003 Feb;22(1):77-81. doi: 10.1016/S0142-9418(02)00052-1. 
15. Um CM, Ruyterl E. Staining of resin-based veneering materials with coffee and tea. Quintessence Int. 1991 May;22(5):377-86.

16. Prayitno $S$, Addy $M$. An in vitro study of factors affecting the development of staining associated with the use of chlorhexidine. J Periodont Res. 1979 Sep;14(5):397-402.

17. Koishi $Y$, Tanoue N, Matsumura $\mathrm{H}$, Atsuta M. Colour reproducibility of a photo-activated prosthetic composite with different thicknesses. J Oral Rehabil. 2001 Sep;28(9):799-804.

18. Johnston WM, Kao EC. Assessment of appearance match by visual observation and clinical colorimetry. J Dent Res. 1989 May;68(5):819-22.

19. Braden M, Clarke RL. Water absorption characteristics of dental microfine composite filling materials I. Proprietary materials. Biomaterials. 1984 Nov;5(6):369-72.

20. Oysaed H, Ruyter IE. Water sorption and Iler characteristics of composites for use in posterior teeth. J Dent Res. 1986 Nov;65(11):1315-8.

21. Akashi A, Matsuya Y, Unemori M, Akamine A. The relationship between water absorption characteristics and the mechanical strength of resin-modified glass-ionomer cements in long-term water storage. Biomaterials. 1999 Sep;20(17):1573-8.

22. Pascual B, Gurruchaga M, Ginebra MP, Gil FJ, Planell JA, Goñi I. Infuence of the modification of P/L ratio on a new formulation of acrylic bone cement. Biomaterials. 1999 Mar;20(5):465-74.

23. Arima T, Murata H, Hamada T. Properties of highly cross-linked autopolymerizing reline acrylic resins. J Prosthet Dent. 1995 Jan;73(1):55-9.

24. Arima T, Murata $\mathrm{H}$, Hamada T. The effects of cross-linking agents on the water sorption and solubility characteristics of denture base resin. J Oral Rehabil. 1996 Jul;23(7):476-80. 